\title{
GLOBAL VIEW
}

\section{Rural sex work in Cambodia: work characteristics, risk behaviours, HIV, and syphilis}

\author{
H Sopheab, P M Gorbach, S Gloyd, H B Leng
}

Sex Transm Infect 2003;79:e2(http://www.stijournal.com/cgi/content/full/79/4/e2)

Objective: To identify prevalence and risks factors for syphilis and HIV among rural female sex workers (FSWs) in Cambodia and to describe differences between rural and urban FSWs.

Methods: Interviews and sera were collected from 114 FSWs and tested for HIV using the Serodia-HIV test and positives confirmed with the enzyme linked immunosorbent assay. Syphilis was tested for with the rapid plasma reagin with passive particle agglutination test for detection of antibody of Treponema pallidum. Study data were merged with data from a study of urban FSWs from Phnom Penh that applied similar questionnaires and sampling design to compare STI prevalence and behaviours.

Results: $42 \%$ of rural FSWs were HIV positive; $22 \%$ had past or current syphilis. In multivariate models HIV was significantly associated with age $\geqslant 25(O R=6.195 \% \mathrm{Cl}: 1.0$ to 36.6$)$, a non-commercial partner in the past year $(O R=$ $0.33,95 \% \mathrm{Cl}: 0.11$ to 0.93$)$, and prevalence of past or current syphilis (OR $=2.9,95 \% \mathrm{Cl}$ : 1.0 to 8.8$)$. There was significantly higher active syphilis $(14 \% \vee 4 \%)$, older mean age $(25 \vee 21)$, fewer daily clients $(2 \vee 5)$, lower monthly income $(\$ 61 \vee \$ 174)$, and longer duration of sex work (2.3 years $\vee 1.4$ years) among rural than among urban FSWs.

Conclusions: These findings reveal a high burden of HIV and syphilis among FSWs in rural Cambodia. As FSWs age and become infected with STI/HIV they may move out of cities into less competitive but less savvy markets; their high mobility may contribute to the expansion of the HIV epidemic into rural Cambodia and lower risk populations.

$\mathrm{T}$ he HIV Sentinel Surveillance (HSS) of Cambodia's National Center for HIV/AIDS, Dermatology and STDs (NCHADS) in 2000 reported HIV rates reflecting a generalised epidemic: $31 \%$ of "direct" female sex workers (DFSWs), $16 \%$ of "indirect" female sex workers (IDFSWs), and 2.3\% of women receiving antenatal care tested positive for HIV. ${ }^{1}$ The estimated prevalence for syphilis was $4 \%-25 \%$ among DFSWs in cities and border provinces in $1996 .{ }^{2}$ Heterosexual intercourse is the predominant mode of transmission for sexually transmitted infections (STI) including HIV and these epidemics are largely attributed to a local sex industry that is both large ( 55000 FSWs estimated in $\left.2001^{3}\right)$ and low cost (\$2-\$4 per brothel sexual encounter). ${ }^{4}$ STI/HIV control in Cambodia is concentrated in cities even though $85 \%$ of the population are rural. ${ }^{5}$ To identify factors contributing to the generalisation of Cambodia's HIV epidemic into rural populations, identify prevalence and risks factors for syphilis and HIV among rural FSWs, and differences between rural and urban FSWs, a study was conducted of FSWs in Kampong Chnnang province where less than $15 \%$ of people live in the provincial capital. ${ }^{6}$

\section{METHODS}

All FSWs in provincial sex establishments ( 23 brothels and six karaoke bars in three districts) were listed (a complete census) and 114 of the 126 FSWs agreed to participate. In December 2000 FSWs were interviewed by female staff using a sexual behaviour questionnaire; then $5 \mathrm{ml}$ of blood was drawn and a unique code number assigned. HIV was tested with Serodia-HIV and positives confirmed by enzyme linked immunosorbent assay (GENSCREEN-HIVl/2 version 2, Sanofi Pasteur). Syphilis was tested for using rapid plasma reagin (RPR) and passive particle agglutination test for detection of antibody of Treponema pallidum (TPPA, Fujirebio, Japan). Subjects testing positive for both RPR and TPPA indicated active syphilis; those positive for TPPA alone were considered having past or current syphilis infection. Those positive on both RPR and TPPA were treated following the national STI guidelines. Subjects were not provided with HIV test results in accordance with the national policy on HIV research.

The study data from 71 DFSWs were merged with data from Phnom Penh from an urban STI prevalence survey conducted the following month (January 2001). Study questionnaires and data collection were designed to be similar to the larger STI survey to allow for combining the data to compare differences between rural and urban FSWs; blood samples from the STI survey were only tested for active syphilis.

The study was approved by the human subjects review board, University of Washington and the Ministry of Health of Cambodia. Data were entered twice in Epi-Info; Stata (Stata Corporation, TX, USA) was used for statistical analysis, associations between HIV/STI and behavioural factors were assessed bivariately using Student's $t$ test and $\chi^{2}$ test/Fisher's exact test. Unadjusted odd ratios (OR) and $95 \%$ confidence intervals (CI) were calculated using univariate logistic regression and a multiple logistic regression for adjusted ORs.

\section{RESULTS}

Overall, $42 \%$ of rural FSWs tested positive for HIV and 22\% for past or current syphilis (table 1). Of the 114 sex workers 71 were brothel based and 43 were karaoke or bar based, their mean age was 24 years, less than $20 \%$ had secondary education, and their mean monthly income was $\$ 60$. In univariate logistic regression having a non-commercial partner (sweetheart) in the past year and age at first commercial sex were associated with HIV. FSWs who worked longer in the brothels were more likely to report always using condoms than FSWs who worked less ( 12 months $v 6$ months, $\mathrm{p}=0.05$ ). FSWs with sweethearts were less likely to be HIV positive but more likely to be younger $(23.9 v 25.2)$, newer to the brothels (5.5 months $v 9.6$ months, $\mathrm{p}=0.03$ ), and working in karaoke bars $(64.3 \% v 39.4 \%, p=0.01)$ than FSWs without sweethearts. In multivariate logistic regression current age (age $\geqslant 25, \mathrm{OR}=$ $6.195 \%$ CI: 1.0 to 36.6 ), having a non-commercial partner in the past year ( $\mathrm{OR}=0.33,95 \% \mathrm{CI}$ : 0.11 to 0.93 ), and being TPPA positive (OR=2.9, 95\% CI: 1.0 to 8.8$)$ were independently associated with HIV. 
Table 1 Univariate logistic regression between HIV seroprevalence and risk factors among all female sex workers (FSWs) in Kampong Chnnang, Cambodia

\begin{tabular}{|c|c|c|c|c|}
\hline & $\begin{array}{l}\text { FSWs } \\
(n=114)\end{array}$ & $\begin{array}{l}\text { HIV+ } \\
(\%)\end{array}$ & OR* & $95 \% \mathrm{Cl} \dagger$ \\
\hline \multicolumn{5}{|l|}{ Current age (years) } \\
\hline$\leqslant 18$ & 14 & 21 & 1 & \\
\hline $19-24$ & 54 & 39 & 2.33 & 0.58 to 9.35 \\
\hline$\geqslant 25$ & 46 & 52 & 4.00 & 0.98 to 16.24 \\
\hline \multicolumn{5}{|l|}{ Education level $\ddagger$} \\
\hline Primary school & 96 & 39 & 1 & \\
\hline Secondary school & 18 & 61 & 2.50 & 0.89 to 7.03 \\
\hline \multicolumn{5}{|l|}{ Monthly income } \\
\hline$\leqslant 200000$ riels & 62 & 40 & 1 & \\
\hline$>200000$ riels & 52 & 44 & 1.17 & 0.55 to 2.47 \\
\hline \multicolumn{5}{|c|}{ Number of clients in the last day } \\
\hline$\leqslant 2$ clients & 91 & 44 & 1 & \\
\hline$>2$ clients & 20 & 40 & 0.85 & 0.31 to 2.27 \\
\hline \multicolumn{5}{|c|}{ Time in current brothels/karaoke establishments } \\
\hline$\leqslant 3$ months & 56 & 41 & 1 & \\
\hline 4-6 months & 12 & 67 & 2.86 & 0.77 to 10.66 \\
\hline$\geqslant 6$ months & 36 & 39 & 0.91 & 0.38 to 2.14 \\
\hline \multicolumn{5}{|c|}{ Condom use with clients } \\
\hline Always & 80 & 49 & 1 & \\
\hline Not always & 19 & 32 & 0.48 & 0.17 to 1.40 \\
\hline \multicolumn{5}{|c|}{ Reported past year sweetheart } \\
\hline No & 58 & 52 & 1 & \\
\hline Yes & 55 & 33 & 0.45 & 0.21 to 0.97 \\
\hline \multicolumn{5}{|c|}{ Previous places of sex work } \\
\hline Other cities/provinces & 35 & 43 & 1.0 & \\
\hline Kampong Chnnang & 77 & 43 & 1.0 & 0.44 to 2.24 \\
\hline \multicolumn{5}{|c|}{ Ethnic group } \\
\hline Cambodian & 74 & 41 & 1 & \\
\hline Others§ & 39 & 46 & 1.25 & 0.57 to 2.74 \\
\hline \multicolumn{5}{|c|}{ Age at first commercial sex } \\
\hline$\leqslant 18$ & 29 & 24 & 1 & \\
\hline $19-24$ & 45 & 44 & 2.51 & $0.89-7.10$ \\
\hline$\geqslant 25$ & 35 & 57 & 4.19 & $1.42-12.36$ \\
\hline \multicolumn{5}{|l|}{ Type of work } \\
\hline IDFSWs (karaoke) & 43 & 35 & 1 & \\
\hline DFSWs (brothel) & 71 & 47 & 1.62 & 0.74 to 3.54 \\
\hline \multicolumn{5}{|l|}{ TPPA } \\
\hline Negative & 89 & 38 & 1 & \\
\hline Positive & 25 & 56 & 2.05 & 0.83 to 5.05 \\
\hline \multicolumn{5}{|l|}{ RPR and TPPA positive } \\
\hline Negative & 100 & 40 & 1 & \\
\hline Positive & 14 & 57 & 2.00 & 0.64 to 6.20 \\
\hline $\begin{array}{l}\text { *Unadjusted odd ratio } \\
\text { than or equal } 5 \text { years, } \\
\text { Vietnamese, Cham, an }\end{array}$ & $\begin{array}{l}\text { †5 \% co } \\
\text { econdary }\end{array}$ & $\begin{array}{l}\text { ence } \\
\text { nore }\end{array}$ & $\begin{array}{l}\text { erval } \\
\text { an } 5 y\end{array}$ & $\begin{array}{l}\text { Primary = less } \\
\text { rs; §̧lncluding }\end{array}$ \\
\hline
\end{tabular}

Significantly more of the 71 DFSWs from Kampong Chnnang tested positive for syphilis than the 150 DFSWs from Phnom Penh ( $14.1 \% v 4 \%, \mathrm{p}=0.007)$ (table 2). The following were significantly different between rural and urban FSWs: current age $(24.7 v 21.3, \mathrm{p}<0.001)$, age at first commercial sex (22.4 $v 20, \mathrm{p}<0.001)$, number of daily clients (1.6 $v$ 5.1, $\mathrm{p}<0.001)$, monthly income $(\$ 61.4 v \$ 174.3, \mathrm{p}<0.001)$, and duration of sex work (2.3 years $v 1.4$ years, $\mathrm{p}=0.004$ ). For illustrative purposes HIV prevalence was compared from Cambodia's 2000 HSS; HIV prevalence among FSWs in Kampong Chnnang was nearly twice as high as among FSWs in Phnom Penh.

\section{DISCUSSION}

In a rural province of a country with a generalised HIV epidemic FSWs were found to have a high burden of disease and an epidemiology divergent from expected patterns. Unlike Vietnam, ${ }^{8}$ FSWs reporting non-commercial partners (sweetheart) in the past year were less likely to be HIV positive than those without such partners, even though few used condoms with these partners. Because FSWs with such partners were younger and newer at sex work, their lower HIV prevalence was more likely to be the result of a shorter duration of exposure than their current behaviour. Also unexpected was that the number of daily clients was not associated with HIV, perhaps because few rural FSWs reported high numbers of daily clients or HIV positive FSWs could have previously had more daily partners at the time of infection. Finally, reported condom use was not associated with HIV/STI. Given that rural FSWs newer to sex work used condoms less than more experienced FSWs, those currently reporting consistent use may have become infected with HIV earlier in their sex career before adopting consistent use. This suggests condom counselling should target new FSWs.

Rural FSWs were twice as likely to be HIV positive and were older than urban FSWs, suggesting that after working in cities, FSWs may move to the provinces and be replaced by younger and less experienced FSWs. Indonesian FSWs working in cities or towns reported returning to their home after retiring from sex work. ${ }^{9}$ Although there is a greater demand for commercial sex in Cambodian cities (urban FSWs report more daily clients than rural FSWs, a higher monthly income, and in a household survey more urban than rural males reported accessing commercial sex in the past year ${ }^{10}$ ) older FSWs may be outcompeted. In the 1999 BSS 70\% of urban

Table 2 HIV and syphilis prevalence, and risk behaviour among rural sex workers in Kampong Chnnang province and urban sex workers in Phnom Penh, Cambodia

\begin{tabular}{|c|c|c|c|c|c|}
\hline & \multicolumn{2}{|c|}{ Kampong Chnnang } & \multicolumn{2}{|c|}{ Phnom Penh } & \multirow[b]{2}{*}{ p Value* } \\
\hline & No (\%) & Mean & No (\%) & Mean & \\
\hline Current age & 71 & 25 years & 150 & 21 years & 0.0001 \\
\hline Age at first sex & 71 & 18 years & 150 & 19 years & 0.45 \\
\hline Age at first commercial sex & 71 & 22 years & 150 & 20 years & 0.0001 \\
\hline Number of clients per day & 71 & 2 & 149 & 5 & 0.0001 \\
\hline Monthly income & 71 & $\$ 61$ & 148 & $\$ 174$ & 0.0001 \\
\hline Cost per client & 71 & $\$ 2$ & 48 & $\$ 2$ & 0.14 \\
\hline Duration of sex work $\dagger$ & 71 & 2 years & 150 & 1 year & 0.004 \\
\hline Brothel size & 68 & 7 & 138 & 6 & 0.35 \\
\hline \multicolumn{6}{|l|}{ Consistent condom use } \\
\hline With client & 68 (79) & & $150(67)$ & & 0.07 \\
\hline With regular clients & $33(76)$ & & 108 (71) & & 0.62 \\
\hline With sweetheart & $18(61)$ & & $58(54)$ & & 0.56 \\
\hline Active syphilis (RPR/TPPA+) & 71 (14) & & $150(4)$ & & 0.007 \\
\hline HIV positive§ & 71 (47) & & $152(26)$ & & NA \\
\hline
\end{tabular}

*Significant level at $p \leqslant 0.05$.

†Duration was calculated by using current age minus age at first commercial sex. fln Kampong Chhnang, the condom use with sweethearts was asked in past week, while in Phnom Penh it was asked in past month.

$\S$ The HIV data in Phnom Penh were taken from the report on HIV Sentinel Surveillance in Cambodia, 2000, National Center for HIV/AIDS, Dermatology and STDs, Ministry of Health. 


\section{Key messages}

- High HIV and syphilis prevalence are reported among brothel based sex workers in one rural province in Cambodia, the country with Asia's fastest growing and now generalised HIV epidemic

- Differences in behaviour and morbidity between types of sex workers (direct versus indirect) within a rural setting are compared-few differences are found suggesting fluidity of sex work between establishments within provinces

- Sexually transmitted diseases and behavioural patterns are compared between these rural sex workers and sex workers in a large city-differences in age and duration of sex work suggest movement of sex workers out of cities to rural provinces as their careers evolve

FSWs reported being in the city less than one year, ${ }^{4}$ yet there are no data on where they go after leaving their jobs.

The high prevalence of disease and risky behaviour among these rural sex workers suggests continuing transmission of HIV outside of the cities into rural areas. The spread of the HIV epidemic in Cambodia has been largely attributed to mobility of male clients who act as sexual bridges by having sex with both FSWs and their wives. ${ }^{11}$ These findings suggest the mobility of FSWs is also important. Sex workers may begin their careers in major cities then relocate to rural provinces after becoming infected with STIs, including HIV. Smaller rural sex markets may pose a greater challenge for sex work to be lucrative, possibly resulting in FSWs to be less likely to insist on condom use by clients that are fewer and less savvy about HIV than urban clients. Approaches to reducing HIV incidence effective globally such as STI detection and treatment, voluntary HIV testing and counselling, and condom promotion have been greatly expanded in Cambodia in urban settings; however, they are also needed in rural areas. HIV prevention programmes have been successfully directed at rural general populations in developing countries (Mwanza study), ${ }^{12}$ and these findings suggest HIV prevention programmes should consider targeting rural sex workers to control further generalisation of STI/HIV epidemics.

\section{ACKNOWLEDGEMENTS}

This study was supported by the International AIDS Research and Training Program (IARTP), University of Washington and funded by the Fogarty International Center, National Institutes of Health (D43TW00007)

The authors would like to thank the National Center for HIV, AIDS, Dermatology and STDs and IMPACT/FHI for providing the STI prevalence data from Phnom Penh. Thanks also to Dr Mun Phalkun, Dr
Kaoeun Chetra, Ms Seng Sopheata, Ms Kao Chantha, and Ms Ek Someth for their assistance during the fieldwork, to Dr Stephen Bezruchka for his guidance in Seattle, the Provincial AIDS Office and Provincial Health Department of Kompong Chnnang, and the Ministry of Health for their collaboration and, finally, the women who participated in the study.

\section{CONTRIBUTORS}

HS designed the data collection instruments, field methods, analysis plan, supervised the fieldwork, and undertook most of the writing; PMG participated in all aspects of the design, analysis, and writing; SG and HBL provided guidance in study design and writing of the manuscript.

\section{Authors' affiliations}

H Sopheab, S Gloyd, Department of Health Services, University of Washington, Seattle, WA, USA

H Sopheab, H B Leng, National Center for HIV/AIDS, Dermatology and STDs, Ministry of Health, Phnom Penh, Cambodia

P M Gorbach, Department of Epidemiology, University of California, Los Angeles, CA, USA

Correspondence to: Dr Pamina M Gorbach, Department of Epidemiology, School of Public Health Box 951772, University of California, Los Angeles, Los Angeles, CA 90095-1772, USA; pgorbach@ucla.edu

Accepted for publication 11 March 2003

\section{REFERENCES}

1 National Center for HIV/AIDS, Dermatology, and STD. Report on HIV Sentinel Surveillance in Cambodia 2000. Phnom Penh: Ministry of Health, 2001

2 Ryan CA, Vathiny OV, Gorbach PM, et al. Explosive spread of HIV-1 and sexually transmitted diseases in Cambodia. Lancet 1998;351:1175.

3 Basili H. Saving sex slaves. Sydney Morning Herald 2001 April 12,

4 Sopheab H, Gorbach P, Leng HB, et al. Cambodia's Behavioral Surveillance Survey, 1999 (BSSI-III). Final report. Cambodia: National Center for HIV/AIDS, Dermatology and STDs, Ministry of Health, February 2000.

5 Ministry of Health. National Health Statistics Report 1998. Cambodia: Ministry of Health, April 1999

6 Ministry of Planning. General Population Census of Cambodia 1998. Phnom Penh: National Institute of Statistics, Ministry of Planning, 1998.

7 National Center for HIV/AIDS, Dermatology and STDs. The transmission and control of STDs and HIV in Cambodia, 1998. Cambodia: National Center for HIV/AIDS, Dermatology and STDs.

8 Thuy NT, Nhung VT, Thuc NV, et al. HIV infection and risk factors among female sex workers in southern Vietnam. AIDS 1998;12:425-32

9 Ahlburg DA, Jensen ER. The economics of the commercial sex industry. In: Ainsworth M, Fransen L, Over M, eds. Confronting AIDS: evidence from the developing world. European Commission and the World Bank, 1998: 162

10 Sopheab H, Phalkun M, Leng HB, et al. Cambodian Household Male Survey 2000 (BSS IV). Cambodia: National Center for HIV/AIDS Dermatology and STDs, Ministry of Health, February 2001:14.

11 Gorbach PM, Sopheab H, Phalla T, et al. Sexual bridging by Cambodian men: potential importance for general population spread of STD and HIV epidemics. Sex Transm Dis 2000;27:320-6.

12 Grosskurth H, Mosha F, Todd J, et al. Impact of improved treatment of sexually transmitted diseases on HIV infection in rural Tanzania: randomised controlled trial. Lancet 1995;346:530-6. 